\title{
Saline stratification and its influence on fine sediment transport in a semi-enclosed tidal lagoon, West Sussex, UK
}

\author{
S. B. Mitchell ${ }^{1}$, H. M. Burgess ${ }^{2}$, D. J. Pope ${ }^{2}$ \& A. Theodoridou ${ }^{2}$ \\ ${ }^{I}$ Department of Engineering Systems, London South Bank University, UK \\ ${ }^{2}$ School of the Environment and Technology, University of Brighton, UK
}

\begin{abstract}
Mathematical models of solute mixing and sediment transport in estuaries rely heavily on the provision of good-quality field data. Observations of salinity, suspended sediment concentration and velocity at one of the tidal limits of a semi-enclosed tidal lagoon in Southern England (Pagham Harbour, West Sussex, UK) are presented, which illustrate how the natural processes of tidal incursion and solute mixing have been heavily modified as a result of the construction of sea walls dating back to the 18th Century. These observations, made immediately downstream of two parallel tidal flap gates by a conductivitytemperature-depth (CTD) profiler, and also using velocity sensors on bedmounted frames to measure the velocity at 2 fixed depths, have yielded a set of results covering 11 tidal cycles over the period 2002-2004. It is clear from the results obtained that over a typical tidal cycle the highest vertical salinity gradients occur in the 1-2 hours immediately after the onset of the flood tide, and that subsequently, energetic mixing acts to rapidly break down this stratification. Under moderate-to-high fresh water flows $\left(>0.3 \mathrm{~m}^{3} / \mathrm{s}\right)$, the break-down in vertical salinity gradient is more gradual, while under low fresh water flows $\left(<0.2 \mathrm{~m}^{3} / \mathrm{s}\right)$, the vertical salinity gradient occurs earlier in the tidal cycle. The data also show that most of the sediment transport is landward, and occurs during flood tides. These observations can help to provide information about the appropriate techniques for managing siltation and pollution, including nutrient transport from sewage effluent waters, in estuaries where hydraulic flap gates are used to control the entry of fresh water.
\end{abstract}

Keywords: tidal lagoon, stratification, suspended sediments, flap gates. 


\section{Introduction}

Many estuaries that are near centres of high population density are subject to a degree of constraint afforded by sea walls and other engineered features, particularly when the surrounding land is lower than the level of maximum tidal high water. While the normal tidal and fluvial circulation processes have been studied in some detail for a range of longer, larger systems [1, 2], for large tidal lagoons [3, 4], and more recently for smaller systems characterised by shallow tidal channels $[5,6]$, relatively little attention has been paid to estuaries and estuary systems characterised by short, heavily engineered channels and constrained intertidal areas. Tidal flap gates, for example, are designed to allow water to drain from the surrounding land during periods of low tidal water level, and to close when the tide reaches a certain level by virtue of the increased pressure of water on the seaward side relative to that on the landward side.

This contribution aims to identify the mechanisms of salt and fine sediment transport that occur in a tidal channel immediately downstream of a set of hydraulic flap gates, by analysing vertical profiles of salinity, velocity and suspended sediment concentration data over 11 tidal cycles at a tidal limit of Pagham Harbour, West Sussex, UK. As a nature reserve and an internationallyrecognised Ramsar site (see www.ramsar.org) with importance for key species of wading birds, understanding the long-term geomorphological evolution of the site is crucial. Particular research questions relate to the identification of the main mechanisms that occur immediately after low water, in other words, directly after the flap gates have closed and the water level on the seaward side of the gates starts to rise. In identifying and monitoring the processes that occur at this point in the tidal cycle, it is also possible to make inferences about the influence of tidal range and fresh water flow on these processes, and to make preliminary estimates of the flood-tide flux of suspended sediment.

\section{Study site and methods}

Pagham Harbour (Area: approx. $2.8 \mathrm{~km}^{2}$ at mean high water level during spring tides, Location: $0^{\circ} 46^{\prime} \mathrm{W}, 50^{\circ} 46^{\prime} \mathrm{N}$, see Figure 1) is a tidal lagoon located on the heavily-populated South coast of England some $30 \mathrm{~km}$ to the East of the major city of Portsmouth. Local tides in the coastal waters outside the lagoon are semi-diurnal with a mean tidal range of between approximately $3.0 \mathrm{~m}$ (Neaps) and $6.5 \mathrm{~m}$ (Springs). The lagoon is connected to the English Channel via a $50 \mathrm{~m}$ wide entrance, and protected by two artificially replenished shingle spits, one each side of the harbour entrance. Fresh water input is low, via a series of small drainage channels (known locally as 'rifes') which drain the surrounding land, indicated by Q1-Q5 on Figure 1. A number of inner sea walls, with tidal flap gates at the entry points of the rifes, protect the surrounding low-lying reclaimed land and prevent saline intrusion upstream. Owing to its elevation, the tidal cycle within the lagoon is asymmetrical, with shorter, faster flood currents (duration approx. $3 \mathrm{~h}$ ) and a longer, slower ebb tide period. Seawater inundation only occurs during the 4-6 hours over high water, and tidal range in the lagoon varies 
between approximately 1.8 and $3.3 \mathrm{~m}$. During the rest of the tidal cycle, the lagoon consists of a network of drainage channels surrounded by mudflats and areas of salt marsh in which water depths in the channels rarely exceed $0.5-1.0 \mathrm{~m}$ anywhere within the lagoon, and are governed at low water by the fresh water flow that enters the lagoon via the rifes. The salinity, measured using the practical salinity scale, therefore varies between 0 at low water and about 32-34 at high water at the tidal limits, regardless of tidal range.

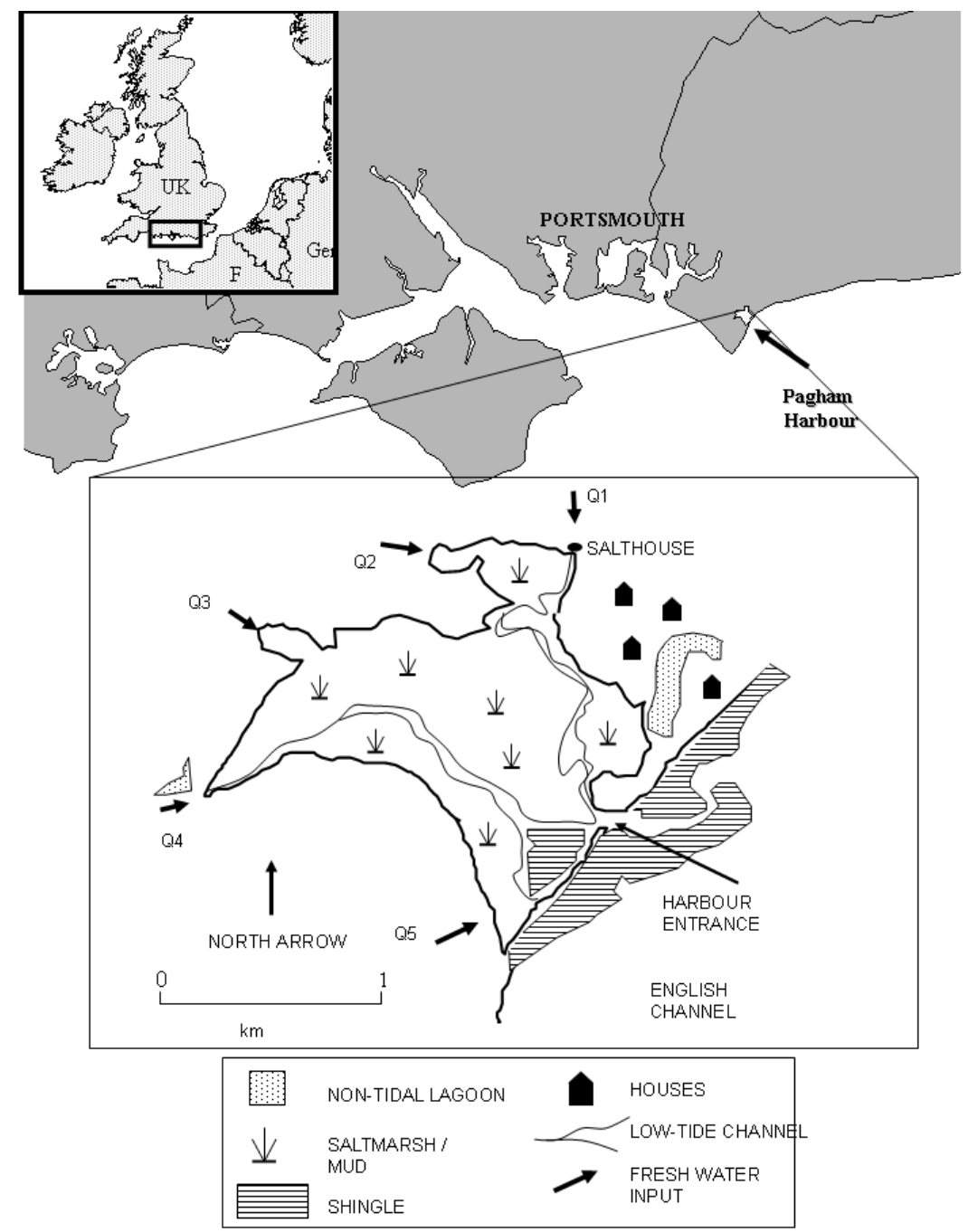

Figure 1: Map of study area showing detail of instrumented site as inset. Low water tidal channels shown as dashed lines. 
The two tidal flap gates under investigation in this study are located in parallel at the Southern end of Pagham Rife (Q1 on Figure 1), and measure approximately $1.2 \mathrm{~m}$ square (total area $2.9 \mathrm{~m}^{2}$ ). In a previous study, hydraulic analyses were undertaken in which a relationship was obtained between low water level immediately downstream of the (open) flap gates and the fresh water flow, which yielded good estimates of the mean tidal fresh water flow on any given tide [7].

Results from a Sea-bird SBE 19-plus conductivity-temperature-depth (CTD) probe (Sea-bird Electronics, Bellevue, WA, USA) with built-in turbidity sensor (Seapoint Sensors, Inc, Exter, NH, USA), and simultaneous velocity measurements using Alec model ACM $210 \mathrm{~V}$ Electromagnetic current meters (Alec Electronics Co. Ltd, Kobe, Japan), were obtained over eight tidal cycles spread over two years at the Salthouse site, in the channel approximately $10 \mathrm{~m}$ downstream of the tidal flap gates (Figure 1). The dates of the surveys are shown in Table 1, together with key hydraulic data. Tidal influence was expressed as peak tidal water depth above the bed, this being a more significant parameter in terms of its effects on the mechanisms at the site. Not all parameters were measured for each deployment due to availability of equipment. The CTD probe was suspended by means of a system of pulleys, scaffold poles and ropes from a frame mounted adjacent to the tidal flap gates. It was winched upwards and downwards with a period of about 10 minutes throughout the 6-8 hours of tidal inundation to obtain values of temperature, salinity and turbidity at different depths throughout the period. Readings were obtained at 30-second intervals. Salinity was obtained from observed conductivity and temperature readings using the built-in Sea-bird software. Two current meters were mounted on a

Table 1: $\quad$ Times of low water (LW), arrival of saline water $\left(\mathrm{t}_{\mathrm{a}}\right)$, peak SSC $\left(\mathrm{SSC}_{\mathrm{P}}\right)$, vertical salinity difference $(\Delta \mathrm{S})$, fresh water flow $\left(\mathrm{Q}_{\mathrm{f}}\right)$, peak tidal water depth $(\mathrm{TH})$.

\begin{tabular}{|l|l|l|l|l|l|l|}
\hline Date & $\begin{array}{l}\mathrm{LW} \\
(\mathrm{GMT})\end{array}$ & $\mathrm{t}_{\mathrm{a}}$ (mins) & $\begin{array}{l}\mathrm{SSC}_{\mathrm{P}} \\
(\mathrm{mg} / \mathrm{l})\end{array}$ & $\Delta \mathrm{S}$ & $\mathrm{Q}_{\mathrm{f}}\left(\mathrm{m}^{3} / \mathrm{s}\right)$ & $\begin{array}{l}\mathrm{TH} \\
(\mathrm{m})\end{array}$ \\
\hline 14.08 .02 & $12: 43$ & 42 & 60 & 7 & 0.16 & 3.3 \\
\hline 07.01 .03 & $11: 20$ & 78 & 105 & $\mathrm{NA}$ & 0.90 & 3.0 \\
\hline 07.01 .03 & $23: 55$ & 72 & 220 & $\mathrm{NA}$ & 0.85 & 3.1 \\
\hline 14.11 .03 & $10: 36$ & 48 & 175 & 20 & 0.17 & 2.7 \\
\hline 12.12 .03 & $09: 45$ & 75 & 100 & 5 & 0.23 & 3.0 \\
\hline 06.02 .04 & $08: 28$ & 78 & 100 & 6 & 0.31 & 3.3 \\
\hline 09.03 .04 & $10: 18$ & 42 & 40 & 2 & 0.25 & 3.5 \\
\hline 18.05 .04 & $08: 11$ & 60 & 50 & 2 & 0.23 & 3.0 \\
\hline 03.06 .04 & $08: 26$ & 48 & 70 & 5 & 0.21 & 3.4 \\
\hline 06.07 .04 & $11: 39$ & 30 & 60 & 2 & 0.16 & 3.4 \\
\hline 3 Aug 04 & $10: 27$ & 30 & 40 & 3 & 0.17 & 3.7 \\
\hline
\end{tabular}


scaffold pole driven vertically into the bed of the tidal channel at a distance of 30 $\mathrm{m}$ from the tidal flap gates and mounted at depths of 0.4 and $1.3 \mathrm{~m}$ above the bed in mid-channel, respectively. The probes were connected to two Squirrel SQ400 data loggers (Grant Instruments Limited, Cambridge, UK) which recorded instantaneous velocity data at 15 -second intervals throughout the experiments.

\section{Results}

Results of near-bed and near-surface salinity and near-bed SSC obtained from the tidal cycle of 14 August 2002 are presented in Figure 2(a), together with the water depth and velocity in Figure 2(b), in which positive values of velocity signify those in the downstream (seaward) direction. The time index along the $\mathrm{x}$ axis has been normalised to show the time after low water in hours. Values for near-bed salinity were obtained using all data from the bottom $0.8 \mathrm{~m}$, and values for near-surface salinity obtained for data where the ratio of distance of the probe above the bed to flow depth was above 0.8 (i.e. $z / d>0.8$ ). It can be seen from Figure 2(a-b) that the reversal of flow which occurs at the onset of the flood tide $(\mathrm{t}=0)$ causes the near-bed velocity to reverse quickly from $0.4 \mathrm{~m} / \mathrm{s}$ to $-0.1 \mathrm{~m} / \mathrm{s}$, then to increase to nearly zero until about $\mathrm{t}=0.8 \mathrm{~h}$ when the velocities suddenly decrease sharply with the arrival of the salt water. Both velocities then gradually increase to nearly zero during the course of the rest of the tidal cycle until the flap gates reopen, and the near-bed velocity returns to its original value (not shown). Best-fit lines are shown in Figure 2(a) that illustrate the vertical salinity difference $(\Delta \mathrm{S})$ during the period $\mathrm{t}=0.8-1.6 \mathrm{~h}$, which reaches a maximum difference at about $\mathrm{t}=1.0 \mathrm{~h}$ of approximately 7.0. There is a clear peak in nearbed SSC $\left(\mathrm{SSC}_{\mathrm{P}}\right)$ at around the time of maximum landward velocity $(\mathrm{t}=1.0 \mathrm{~h})$, of about $60 \mathrm{mg} / \mathrm{l}$, after which the SSC returns to background level with the settling of sediment into the channel and onto the surrounding intertidal areas. Figure 2(c) shows the evolution of vertical salinity profiles between $\mathrm{t}=0.74 \mathrm{~h}$ and $\mathrm{t}=$ $1.27 \mathrm{~h}$ after low water and demonstrate the existence of a short-lived saline wedge between these times. For clarity the results are only shown for the downward movement of the CTD from near-surface to near-bed. It should also be noted that for the middle two profiles considerable variation may be seen in salinity within the near-surface region. The value for $\Delta S=7.0$ for this deployment is therefore an average value that does not take this variation into account. For the higher fresh water flow $\left(\mathrm{Q}_{\mathrm{f}}=0.31 \mathrm{~m}^{3} / \mathrm{s}\right)$ observed on 6 February 2004, the observed values of salinity and SSC are slightly different (Figure 3). The figure shows greater differences between near-bed and near-surface salinity, which take a longer time to reduce, and in this case the arrival of the sedimentladen water occurs before the arrival of the more saline water, indicating sediment availability in the fresh water within the lagoon at low water. The vertical salinity profiles between $t=1.28 \mathrm{~h}$ and $t=1.87 \mathrm{~h}$ in Figure $3(\mathrm{~b})$ show the same breakdown of stratification as for the low fresh water flow case, but this occurs 30 minutes later on in the tidal cycle.

The full set of results for all 11 deployments are not presented here in detail, as the features described above are common to each tidal cycle, generally 
differing only in their timing and magnitude. Table 1 summarises all these features for each deployment. Also shown is the length of time in minutes after low water of the arrival of the saline water.

(a)

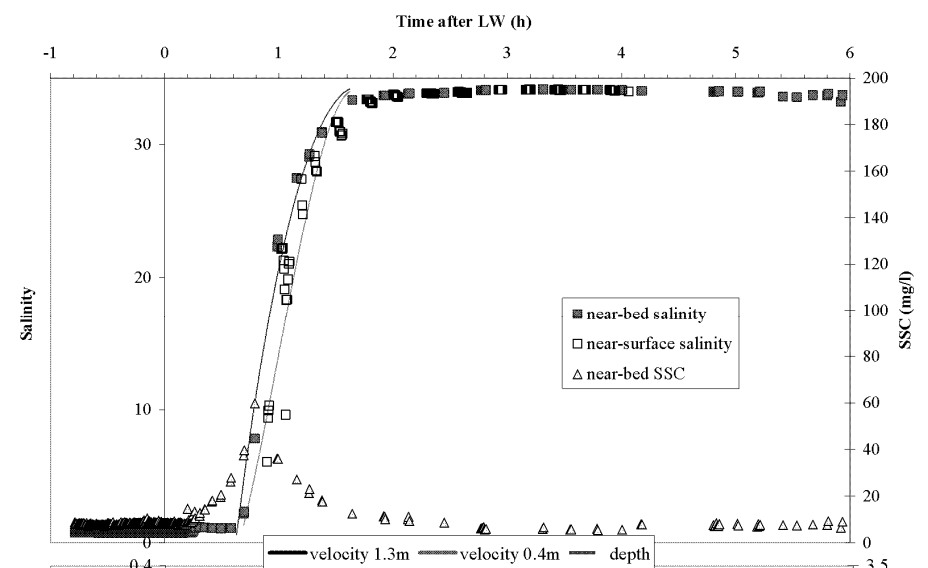

(b)

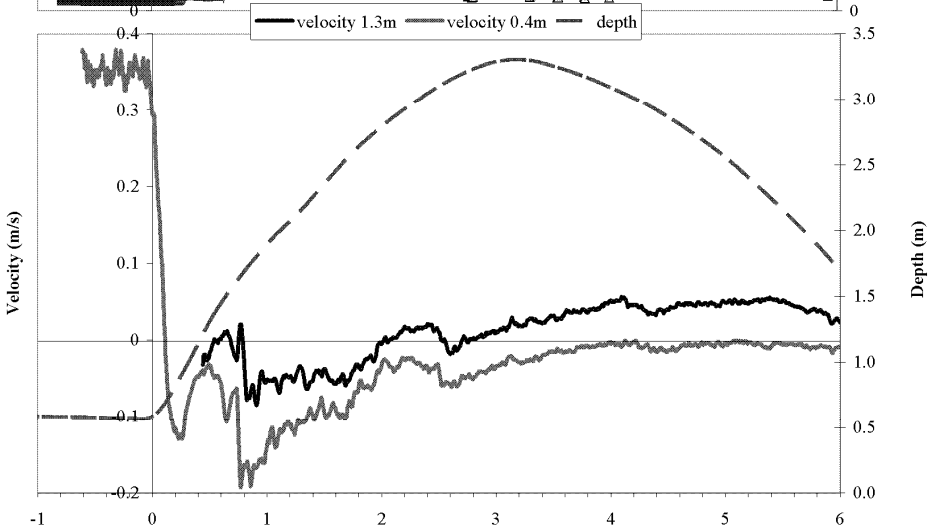

(c)

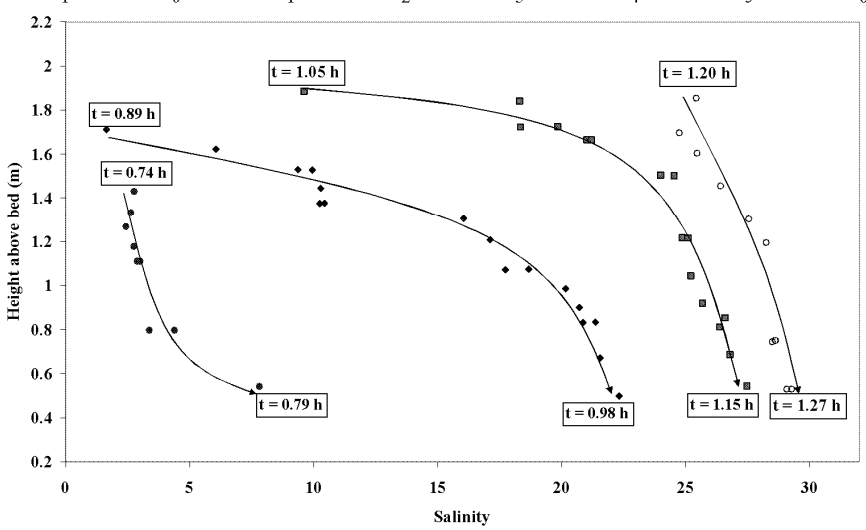

Figure 2: (a) Salinity, SSC (b) velocity, flow depth (c) vertical profiles 14.08.02. 
(a)

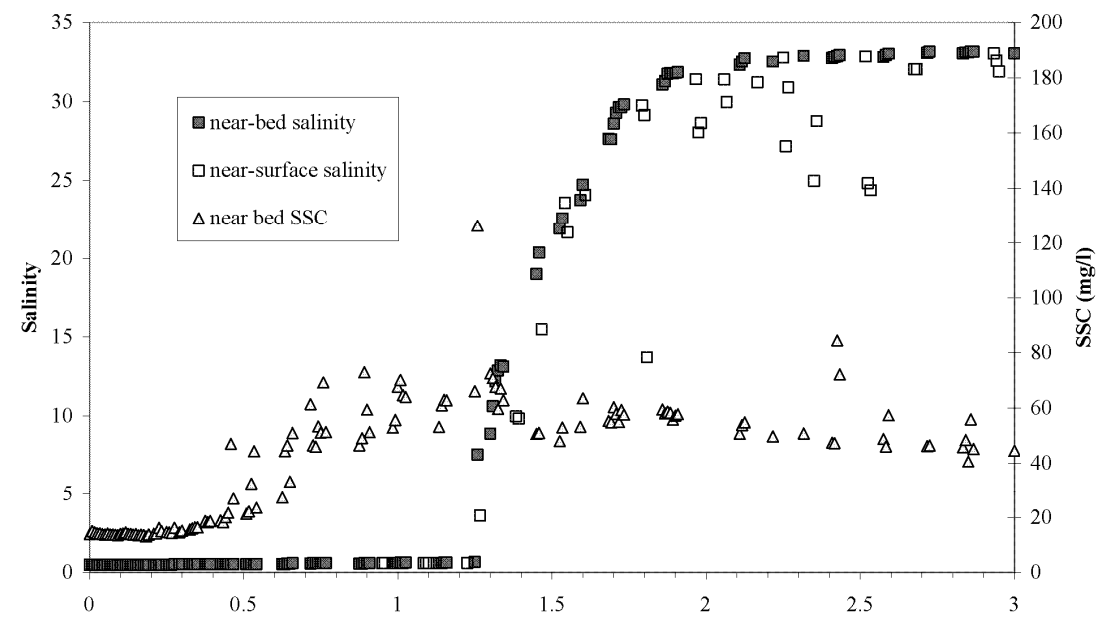

(b) Time after LW (h)

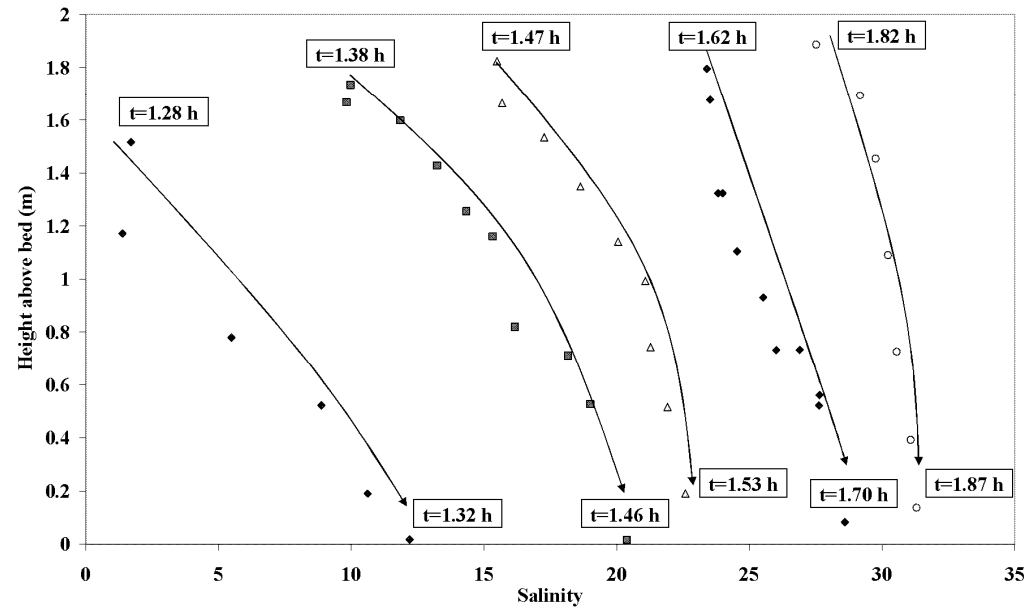

Figure 3: $\quad$ (a) Salinity, SSC (b) vertical profiles 06.02.04.

\section{Discussion}

Inspection of the velocity, salinity and SSC data shown in Figures 2 and 3 yields important information about the mechanisms of salt and sediment transport at the study site, and in particular, enables a better understanding of the ways in which the tidal flap gates act to modify these mechanisms. Despite the variations in observed values between similar deployments, the general mechanisms can be described by the following series of 3 steps:

(1) At the end of each ebb tide, the tidal channel downstream of the flap gates contains fresh water. This is forced landwards by the onset of the flood tide, and 
is advected upstream from within the main body of the lagoon. Saline water is not observed until 30-80 minutes after low water, during which time velocities in the channel are low or zero as the fresh water is 'trapped' immediately downstream of the flap gates.

(2) On arrival of the saline water, three features may be observed simultaneously. Firstly, velocities rise sharply (in the manner of a flood-tide 'pulse' described in [8]), but are considerably higher in the near-bed region. Higher up in the water column, the velocities are lower or even show a modest flow seaward for a short period. Secondly, concentrations of suspended sediment rise sharply, reaching a peak before the sediment starts to settle to the bed of the channel and the surrounding intertidal areas. Thirdly, for the first 30-45 minutes after the arrival of the saline water, a vertical salinity stratification effect is seen as a saline wedge is formed under the trapped fresh water.

(3) Over the 60-90 minutes following the arrival of the saline water, the observed velocities fall to around zero, as mixing takes place and salinity reaches a constant value of 32-34, and sediment concentrations fall to near-zero as sediment settles to the surrounding inter-tidal areas, causing a net deposition described elsewhere $[9,10]$. It is instructive to compare directly Figure 2(c) and 3(b) where a difference in fresh water flow between the two tides causes break down of stratification to occur later, but more effectively, for the higher fresh water flow case.

The relative time taken for the saline water to arrive after low water, and the magnitudes of salinity stratification and peak SSC appear to be correlated with peak tidal water level and (more distinctly) fresh water flow (Figure 4). While

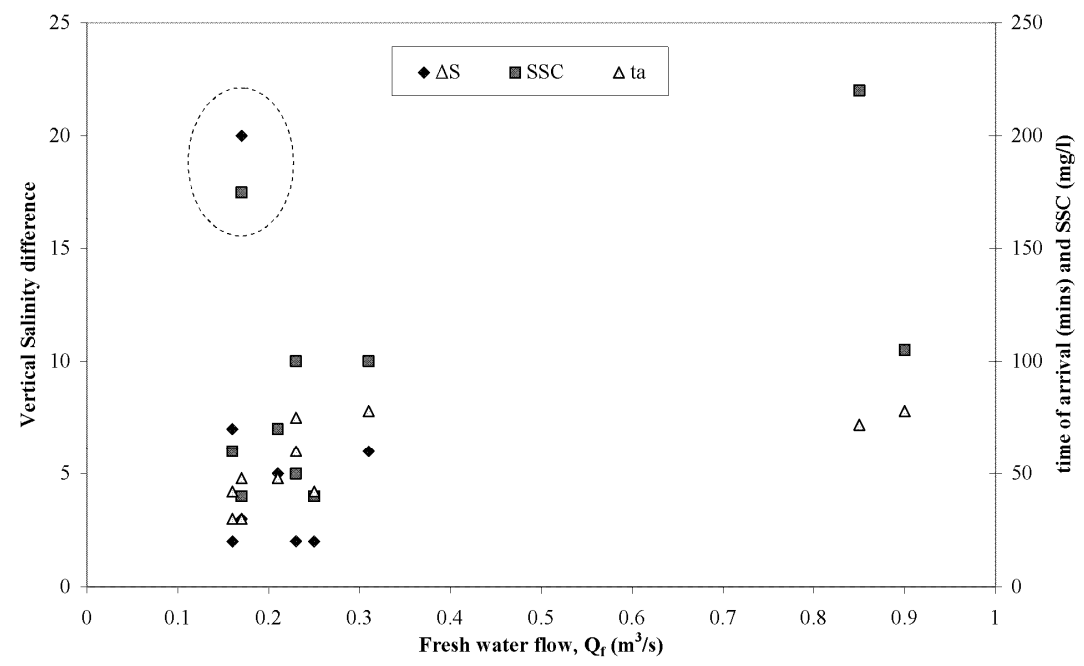

Figure 4: $\quad$ Vertical salinity difference $(\Delta S)$, SSC and time of arrival of saline water $\left(\mathrm{t}_{\mathrm{a}}\right)$ against fresh water flow at LW. Neap tide points encircled. 
general trends in these relationships may be observed, it is clear that here too there is considerable scatter, not least because these variables also depend on peak tidal water level (Table 1), and possibly on local wind speed, although the effect of both these factors is likely to be relatively minor as the peak tidal water depths are similar and the study site is relatively well sheltered. However, it is clear that wind speed and direction may control the generation of short period waves and the resulting erosion of bed sediment [4], although it has not been possible to quantify this effect in this case due to a lack of wind data. The fresh water flow rate also acts to control the arrival of the saline water (Figure 4), both as a function of stored fresh water already in the lagoon and as a function of the tidal water level required to overcome the momentum of the emerging 'jet' of water from the tidal flap gates. This observation is also reported by Kawanisi [11] where a periodic fresh water flow release into tidal waters is also described. Finally in relation to Figure 4 (and also in Table 1) it can be seen that the neap tide of 14 November 2003 is characterised by much higher values of maximum vertical salinity difference and SSC, possibly caused by lower tidal velocities leading to a reduction in the efficiency with which vertical mixing takes place. Further measurements are required to verify this feature, however.

\section{Acknowledgements}

The authors would like to thank Bob Gayler for his valued assistance on the fieldwork campaigns described in this contribution. The assistance of Rob Carver at West Sussex County Council is also gratefully acknowledged.

\section{References}

[1] Cho Y.-K., Park L.-H., Cho C., Lee I.T., Park K.-Y. \& Oh C.W., Multilayer structure in the Youngsan Estuary, Korea. Estuarine, Coastal and Shelf Science 61, 325-329, 2004.

[2] Simpson J.H., Williams E., Brasseur L.H. \& Brubaker J.M., The impact of tidal straining in a partially stratified estuary. Continental Shelf Research 25, 51-64, 2005.

[3] Valle-Levinson A., Delgado, J.A. \& Atkinson L.P., Reversing Water Exchange Patterns at the Entrance to a Semiarid Coastal Lagoon. Estuarine, Coastal and Shelf Science 53, 825-838, 2001.

[4] Dal Monte L. \& Di Silvio G., Sediment concentration in tidal lagoons. A contribution to long-term morphological modelling. Journal of Marine Systems 51, 243-255, 2004

[5] Medina-Gomez I. \& Herrera-Silveira J.A., Spatial characterization of water quality in a karstic coastal lagoon without anthropogenic disturbance: a multivariate approach. Estuarine, Coastal and Shelf Science 58, 455-465, 2003.

[6] Trevethan M., Chanson H. \& Takeuchi M., Continuous high-frequency turbulence and suspended sediment concentration measurements in an upper estuary. Estuarine, Coastal and Shelf Science 73, 341-350, 2007. 
[7] Mitchell S.B., Tinton E. \& Burgess H.M., Analysis of flows and water levels near tidal flap gate. Proceedings of the Institution of Civil Engineers: Maritime Engineering 159, 107-112, 2006.

[8] Warner J.C., Schoellhamer, D.H., Ruhl, C.A. \& Burau, J.R., Floodtide pulses after low tides in shallow subembayments adjacent to deep channels. Estuarine, Coastal and Shelf Science 60, 213-228, 2004.

[9] Mitchell, S.B., Burgess, H.M. \& Pope, D.J., Stratification and fine sediment transport mechanisms in a semi-enclosed tidal lagoon (Pagham Harbour, W Sussex). Water and Environment Journal, 20, 248-255, 2006.

[10] Cundy A.B., Long A.J., Hill C.J., Spencer C., \& Croudace I.W., Sedimentary Response of Pagham Harbour, Southern England to barrier breaching in AD 1910. Geomorphology 46, 163-176, 2002.

[11] Kawanisi K., Structure of turbulent flow in a shallow tidal estuary. Journal of Hydraulic Engineering 130, 360-370, 2004. 